\title{
Green synthesis of cavity-containing manganese oxides with superior catalytic performance in toluene oxidation
}

Tomás García *1,a , José Manuel López a , Álvaro Mayoral b, Yaping Zhang ${ }^{\mathrm{b}}$, Raul Arenal c,d, Daniel Alonso-Domínguez e , María Pilar Pico ${ }^{\text {f }}$, María Luisa López ${ }^{\text {e }}$, Ana Dejoz ${ }^{\text {g, }}$ Inmaculada Álvarez-Serrano *2,e , Rut Sanchis ${ }^{\mathrm{g}}$, Benjamín Solsona*3,g

a. Instituto de Carboquímica (ICB-CSIC), C/Miguel Luesma 4, 50018 Zaragoza, Spain;:

b. $\quad$ Centre for High-Resolution Electron Microscopy (CћEM), School of Physical Science and Technology, ShanghaiTech University, 393 Middle Huaxia Road, Pudong, Shanghai, 201210, China.

c. Laboratorio de Microscopías Avanzadas, Instituto de Nanociencia de Aragón, Universidad de Zaragoza, 50018 Zaragoza, Spain

d. ARAID Foundation, 50018 Zaragoza, Spain.

e. Departamento de Química Inorgánica, Facultad de Ciencias Químicas, Universidad Complutense de Madrid; 28040 Madrid, Spain;+

f. Sepiolsa, Avda. del Acero, 14-16, Pol. UP-1 (Miralcampo), 19200 Azuqueca de Henares, Spain; maria.pico@sepiolsa.com

g. Departament d'Enginyeria Química, ETSE, Universitat de València, Av. Universitat, 46100 Burjassot, Valencia, Spain.

*Corresponding Authors: *1 tomas@icb.csic.es; *2 ias@ucm.es ,*3 Benjamín.solsona@uv.es 


\begin{abstract}
Manganese oxide prepared by a simple hydrothermal method is highly active and stable in both lab and quasi industrial conditions for the total oxidation of toluene, achieving full conversion at only $150{ }^{\circ} \mathrm{C}$ in the presence of 4 wt.\% water. Moreover, this performance is stable for several cycles. The enhanced catalytic performance has been related the presence of highly reactive oxygen surface species. This species are probably promoted by $\mathrm{Mn}_{3} \mathrm{O}_{4}$ nanoparticles with $\mathrm{Mn}^{3+}$ at the tetragonal distorted cationic sites, likely compensated by structural water at the anionic sites. The presence of structural water can be related to the formation of internal cavities/vesicles in the $\mathrm{Mn}_{3} \mathrm{O}_{4}$ crystalline structure.
\end{abstract}

Keywords: manganese oxide; cavities; structural water; toluene; VOCs oxidation. 


\section{Introduction}

In the last decades, oxides of non-noble transition metals have been extensively investigated as catalysts for the total oxidation of volatile organic compounds (VOCs), due to the high price of the conventional catalysts which are based on noble metals (NM) [1,2]. Moreover, these NM-based catalysts permit to operate at temperatures ranging between 100 and $200{ }^{\circ} \mathrm{C}$. Among the non-NM oxides based catalysts; we can highlight pure and supported metal oxides of cobalt, manganese or iron [3-5]. Manganese oxide catalysts have demonstrated to be highly active in the total oxidation of one-ring aromatics [6-8] and other subsets of VOCs [9-12]. Different synthetic routes, e.g. solid state, hydrothermal, molecular sieve techniques, lead to manganese oxide-based catalysts with high stability and great catalytic performance in the oxidation of aromatic compounds $[13,14]$, e.g. a solvothermal technique combined with a calcination at $500^{\circ} \mathrm{C}$, reported as the most adequate for obtaining $\mathrm{Mn}$ (III) oxides-based catalysts [15]; and hydrolysis driven redox reactions leading to manganese oxide catalysts highly tolerant to moisture $[16,17]$.

Hence, hydrothermal processes both in continuous and batch regimes have been employed for synthesizing inorganic particles in a wide variety of research fields, from functional ceramics and electronics to catalysis, biomass processing and energy storage devices [18-20]. Taking into account simplicity, low-cost and controllability criteria, solution-based processes stand out other synthetic strategies as they present saving energy benefits together with innocuous manipulation and tiptop control over particle size and morphology [21]. Hydrothermal routes are based on the chemical reactions and solubility changes of substances in a sealed heated aqueous solution above ambient temperature and pressure to grow nanocrystals [22]. Hence, in recent literature these environmentally benign hydrothermal techniques have been successfully employed for 
obtaining a great variety of materials with enhanced response for different specific fields; i.e. photocatalytic properties of $\mathrm{MoS}_{2}$ [23], pseudocapacitive properties of NiS [24], photoelectrochemical performance of Sn-doped iron oxides [25], catalytic activity of (Ti/Sn) $\mathrm{O}_{2}$ [26], electrochemical efficiency of organometal halide perovskites [27], supercapacitor response of hybrid electrodes [28], etc. In particular, manganese oxides with improved catalytic and electrochemical response [29] or enhanced adsorption performance [30] could be obtained by hydrothermal routes. Besides, solvothermal processes also permit to obtain nanoparticles with different morphologies and tuneable nanoarchitectures of functional materials [31]

Thus, it would be highly interesting to synthesize manganese oxides in a simple, sustainable and straightforward way maintaining the high reactivity and excellent stability. In this sense, hydrothermal synthesis, involving water as the only solvent, is revealed as one of the most simple, promising and green ways to prepare catalytically active materials [32]. Among the different manganese oxide crystalline phases, S.C. Kim et al. [11] reported that $\mathrm{Mn}_{3} \mathrm{O}_{4}$ is the most active phase in the total oxidation of benzene and toluene, which was associated to the best redox properties and the highest oxygen mobility. Later, other authors pointed out the high efficiency of $\gamma$-MnO2 catalyst [8], interpreted on the basis of its three-dimensional macroporous and mesoporous morphology. In fact, VOC oxidation over these catalysts usually occurs through a Mars and van Krevelen (MVK) mechanism [33], where the hydrocarbon molecule is oxidised by lattice oxygen from the manganese oxide. The lattice oxygen is then replenished by the reduction of gaseous oxygen. Therefore, the availability and reactivity of surface oxygen species affect the activity of manganese oxides to a great extent, being the key parameter to develop high performance catalysts [34]. 
Herein, we report that a cavity-containing manganese oxide catalyst obtained by facile, low-cost and environmentally friendly hydrothermal (HT) process shows an outstanding catalytic activity in the removal of toluene by total oxidation. The remarkable activity has been associated to the presence of internal cavities where water molecules are occluded, leading to very reactive surface oxygen species.

\section{Experimental}

\subsection{Preparation method}

Manganese oxide samples Mn-HT (hydrothermal) and Mn-ST (solvothermal) were prepared from $0.1 \mathrm{M}$ manganese (II) acetate, $\mathrm{Mn}\left(\mathrm{C}_{2} \mathrm{H}_{3} \mathrm{O}_{2}\right)_{2} \bullet 4 \mathrm{H}_{2} \mathrm{O}$ (99\%, Aldrich), solutions. The solvent was pure aqueous or ethylene glycol-water in 1:1 volume ratio, respectively. Ammonia was then added to adjust the $\mathrm{pH}$ value at 11 and the precipitation was facilitated. The suspensions were further introduced in autoclaves and treated at $180{ }^{\circ} \mathrm{C}$ for 24 hours. The obtained precipitates were then filtered and dried in a stove at $100{ }^{\circ} \mathrm{C}$.

\subsection{Catalyst characterization}

Nitrogen adsorption measurements were performed on a Micromeritics ASAP 2010 physisorption analyzer at 77K. Brunauer-Emmett-Teller (BET) and Barret-JoynerHalenda $(\mathrm{BJH})$ methods were used for the surface area and pore size distribution determination using $\mathrm{N}_{2}$ adsorption data. Samples were previously outgassed for at least 4 hours at $120^{\circ} \mathrm{C}$.

X-ray powder diffraction (XRD) patterns were registered at room temperature with a PAN analytical X'PERT POWDER diffractometer using $\mathrm{Cu}(\mathrm{K} \alpha)$ radiation with $\alpha$ $=1.5418$ A. Fullprof program was used for Rietveld refinement and pattern matching analysis. 
X-ray photoelectron spectroscopy (XPS) measurements were made on a Kratos Axis ultra DLD photoelectron spectrometer using a non-monochromatized $\mathrm{Mg} \mathrm{K \alpha} \mathrm{X}$-ray source $(\mathrm{h} v=1253.6 \mathrm{eV})$. Analyser pass energy of $50 \mathrm{eV}$ was used for survey scans and $20 \mathrm{eV}$ for detailed scans. Binding energies were referenced to the C1s peak from adventitious carbonaceous contamination, assumed to have a binding energy of 284.8 eV. XPS data were analysed using CasaXPS software. All the peaks of the corrected spectra were fitted with a Gaussian-Lorentzian shape function to peak fit the data. Iterations were performed using the Marquardt method. Relative standard deviations were always lower than $1.5 \%$.

Temperature programmed reduction (TPR) analyses were carried out in a Micromeritics Autochem 2920 instrument equipped with a thermal conductivity detector, operated under a $50 \mathrm{~mL} \mathrm{~min}^{-1} 10 \% \mathrm{H}_{2} / \mathrm{Ar}$ flow at temperatures between -50 and $800{ }^{\circ} \mathrm{C}$, with a heating rate of $10^{\circ} \mathrm{C} \min ^{-1}$.

Spherical aberration corrected (C $\mathrm{C}_{\mathrm{s}}$-corrected) Scanning Transmission Electron Microscopy (STEM) observation have been carried out in a Cold FEG JEOL Grand ARM 300, with double corrector, allowing a point resolution of $0.6 \AA$, equipped with the JEOL SDD EDS system (100mm2 x 2), a dual EELS Gatan 965 GIF Quantum ER; and in a FEI-Titan Low-Base microscope equipped with a $\mathrm{C}_{\mathrm{s}}$ probe corrector, a monochromator and an ultra-bright X-FEG electron source. All measurements were performed at $300 \mathrm{kV}$. Prior observations, the samples were highly dispersed in ethanol for few minutes and few drops of the suspension formed were deposited onto holy carbon copper grids.

The SEM analyses were recorded in JEOL 7800 Prime. In order to acquire the best resolution and allow the observation of the surface of the crystallites, samples were not coated with either gold or carbon. Instead, we adopted gentle beam mode to decrease 
the chromatic aberration. Namely, the gun voltage applied was $5.5 \mathrm{keV}$, with a decelerating voltage $-5 \mathrm{keV}$ on the sample holder, giving a final landing energy of 0.5 $\mathrm{keV}$ on the samples. In order to avoid any misinterpretation, the samples observed in the SEM were the same ones as those observed in the TEM. Therefore, they were supported on carbon coated TEM Cu grids.

Thermogravimetric analyses (TGA) were carried out in a Perkin Elmer Pyris thermogravimeter, at $10{ }^{\circ} \mathrm{C} \min ^{-1}$ heating/cooling rate, under nitrogen and oxygen atmospheres.

\subsection{Catalytic tests}

The catalytic activity was determined in a fixed bed micro-reactor with the reaction temperature controlled by employing a thermocouple placed in the catalyst bed. In most of the experiments the amount of toluene used was maintained in $200 \mathrm{vppm}(0.02 \%$ molar) and the gas hourly space velocity was fixed in GHSV $=6,000 \mathrm{~h}^{-1}$. In the standard experiments $99.98 \%$ of the feed consisted of synthetic gas (oxygen and helium in a 21/79 molar ratio) to give a $\mathrm{C}_{7} \mathrm{H}_{8} / \mathrm{O}_{2} / \mathrm{He}=0.02 / 21.0 / 79.0$ molar ratio. In the experiments with water in the feed two amounts, 4 and 10 molar \%, were used. Thus the feed was $\mathrm{C}_{7} \mathrm{H}_{8} / \mathrm{H}_{2} \mathrm{O} / \mathrm{O}_{2} / \mathrm{He}=0.02 / 4.0 / 20.2 / 75.8$ or $0.02 / 10.0 / 18.9 / 71.1$ molar ratios. In the experiments with $\mathrm{CO}_{2}, 2$ molar \% of $\mathrm{CO}_{2}$ was added to the feed maintaining the $\mathrm{O}_{2} / \mathrm{He}$ ratio constant. Thus, the feed employed was $\mathrm{C}_{7} \mathrm{H}_{8} / \mathrm{CO}_{2} / \mathrm{O}_{2} / \mathrm{He}=$ 0.02/2.0/20.6/77.4 molar ratios whereas in the experiment with $\mathrm{H}_{2} \mathrm{O}$ and $\mathrm{CO}_{2}$ was $\mathrm{C}_{7} \mathrm{H}_{8} / \mathrm{H}_{2} \mathrm{O} / \mathrm{CO}_{2} / \mathrm{O}_{2} / \mathrm{He}=0.02 / 10.0 / 2.0 / 18.5 / 69.5$ molar ratios. Some experiments were undertaken with very high gas hourly space velocity GHSV $=240,000 \mathrm{~h}^{-1}$ maintaining the $\mathrm{C}_{7} \mathrm{H}_{8} / \mathrm{O}_{2} / \mathrm{He}=0.02 / 21.0 / 79.0$ molar ratio. The reactants and reaction products were analyzed using an online gas chromatograph with TCD and FID detectors. Two chromatographic columns were used: (i) Porapak Q (for hydrocarbons and $\mathrm{CO}_{2}$ ) and (ii) 
Molecular Sieve 5A (for oxygen and carbon monoxide). The reaction temperature was employed in the $100-350^{\circ} \mathrm{C}$ range. Conversion was calculated by two methods, through the differences between the inlet and outlet concentrations of toluene and by using the area of the reaction products $\left(\mathrm{CO}_{2}\right)$ and that of the reactant without reacting. These two procedures lead us to adjust the carbon balance with an accuracy of $\pm 5 \%$. Two analyses were done at each temperature after steady state was attained (ca. 30 min before the first analysis) and the results were averaged. A blank run was conducted in an empty reactor without catalyst until $350^{\circ} \mathrm{C}$, showing negligible $(<1 \%)$ conversion.

\section{Results and discussion}

The catalytic performance has been studied by plotting the toluene conversion with the reaction temperature using low space velocities but in the industrial range. Figure 1 shows the evolution of the toluene conversion with the reaction temperature for the two manganese oxide catalysts synthesised. A blank run was conducted in an empty reactor without catalyst until $350{ }^{\circ} \mathrm{C}$, showing negligible ( $\left.<1 \%\right)$ conversion. For our samples, $50 \%$ conversion is achieved at 125 and $160{ }^{\circ} \mathrm{C}$ for Mn-HT and Mn-ST, respectively. Moreover, the $80 \%$ conversion is achieved at 150 and $200{ }^{\circ} \mathrm{C}$ for $\mathrm{Mn}-\mathrm{HT}$ and Mn-ST, respectively. It is noteworthy the low temperature, $175{ }^{\circ} \mathrm{C}$, required for total toluene conversion using the most active catalyst, Mn-HT. In order to check the stability of the most active material, several catalytic cycles were conducted on Mn-HT. Figure 1 also shows the corresponding curves for six consecutive catalytic cycles and no appreciable differences were observed among the cycles, pointing out that this catalyst is highly stable. 


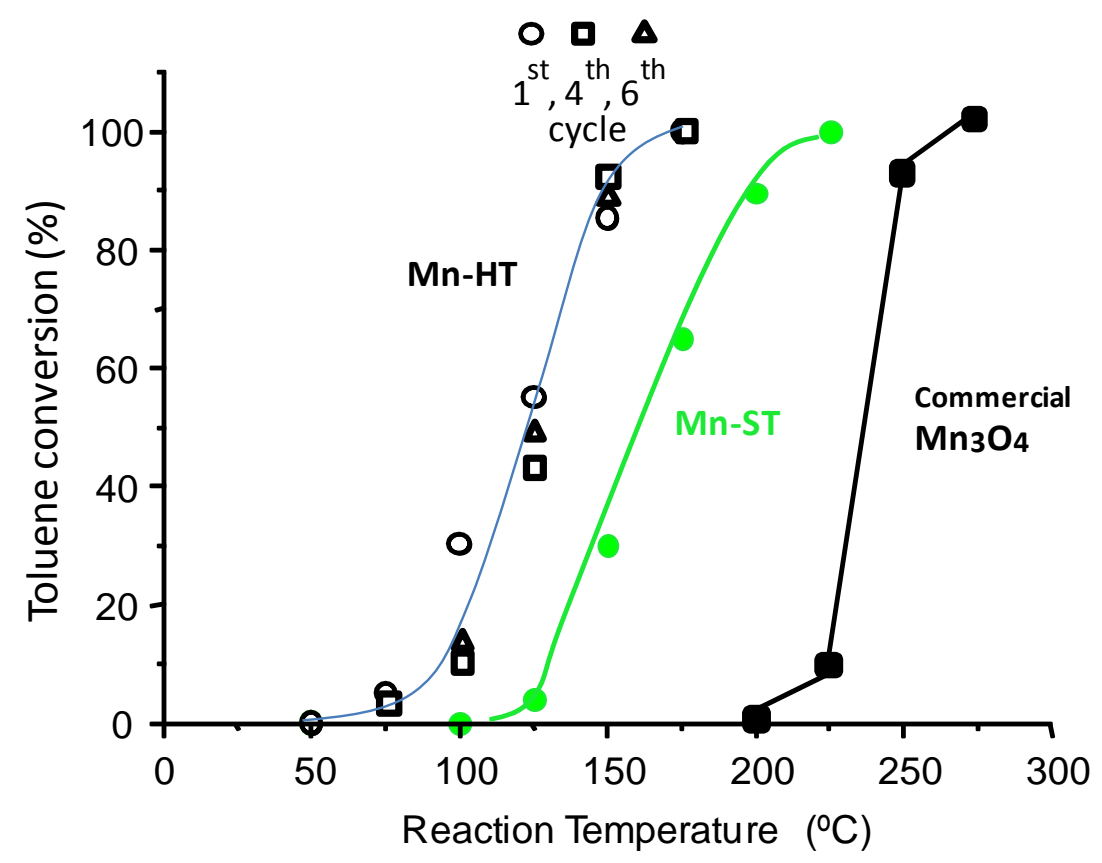

Figure 1. Variation of the toluene conversion with the reaction temperature for manganese oxide catalysts. 200 ppm in synthetic air. GHSV $=6000 \mathrm{~h}^{-1}$.

Table 1 shows the comparison in terms of activity between our Mn-HT and Mn-ST materials and some catalysts reported in the literature, probing that the both catalysts prepared in this work, especially under hydrothermal conditions, have an outstanding good catalytic performance in the catalytic oxidation of toluene.

Table1. Comparison of the catalyst activity between this work and literature.

\begin{tabular}{ccccc} 
Catalyst & $\mathrm{T}_{50}\left({ }^{\circ} \mathrm{C}\right)$ & $\mathrm{T}_{80}\left({ }^{\circ} \mathrm{C}\right)$ & GHSV $\left(\mathrm{h}^{-1}\right)$ & Ref. \\
\hline $\mathrm{Mn}-\mathrm{HT}$ & 125 & 150 & 6000 & This work \\
$\mathrm{Mn}-\mathrm{ST}$ & 165 & 200 & 6000 & This work \\
$\mathrm{Mn}-\mathrm{HT}$ & 250 & 260 & 240000 & This work \\
$\mathrm{Mn}-\mathrm{ST}$ & 265 & 280 & 240000 & This work \\
$\mathrm{Mn}_{2} \mathrm{O}_{3}$ & 256 & -- & -- & 15 \\
$\mathrm{Mn}_{3} \mathrm{O}_{4}$ & 220 & 230 & 19100 & 35 \\
$\mathrm{Mn}_{3} \mathrm{O}_{4}$ & 230 & 240 & 180000 & 36 \\
$\mathrm{Mn}_{3} \mathrm{O}_{4}$ & 240 & 248 & -- & 11 \\
$\mathrm{Mn}_{2} \mathrm{O}_{3}$ & 275 & 280 & -- & 11 \\
$\mathrm{MnO}_{2}$ & 345 & 353 & -- & 11 \\
\hline
\end{tabular}

Manganese oxide hydrothermally prepared (Mn-HT) can totally remove toluene using low space velocities at very low temperature $\left(175^{\circ} \mathrm{C}\right)$. This behaviour is stable and after 
6 cycles similar light-off curve is observed. This stable performance is likely due to the fact that the temperature this material has been previously heat-treated $\left(180^{\circ} \mathrm{C}\right)$ is higher than that required for total conversion $\left(175^{\circ} \mathrm{C}\right)$ and then the structural and surface modifications after the catalytic tests are not important. However, using high space velocities the temperatures required for total conversion already exceed $180^{\circ} \mathrm{C}$ and then a drop in the reactivity is observed. This drop has been demonstrated undertaking an experiment at low space velocity with catalyst previously used at high space velocity. Then it is observed an important activity fall. For example, using low space velocity $50 \%$ conversion is obtained at $125^{\circ} \mathrm{C}$ with the fresh or catalysts used until $175^{\circ} \mathrm{C}$; however, $50 \%$ conversion is obtained at ca. $175^{\circ} \mathrm{C}$ with the catalyst previously used at high space velocity (this experiment required ca. $275^{\circ} \mathrm{C}$ for total conversion).

As Mn-HT is the most active catalyst, different reaction conditions were studied. In the industrial effluents, VOCs are usually emitted in streams containing other components, mainly water and carbon dioxide. Accordingly, the performance of Mn-HT catalyst was evaluated at $125{ }^{\circ} \mathrm{C}$ in the presence of different concentrations of these compounds (Figure 2). In the case of the addition of water to the feed, increasing amounts of $\mathrm{H}_{2} \mathrm{O} \%$ up to $10 \mathrm{~mol} \%$ were used. Interestingly, decreasing activity is not appreciated in any case. Even at low $\mathrm{H}_{2} \mathrm{O}$ concentrations a slight positive effect is attained. Additionally, a complete cycle was also run using water in the feed. Interestingly, total conversion is observed at only $150^{\circ} \mathrm{C}$ which is lower than that temperature at which total conversion is achieved in the absence of water $\left(175^{\circ} \mathrm{C}\right)$ (see Figure 1$)$. 

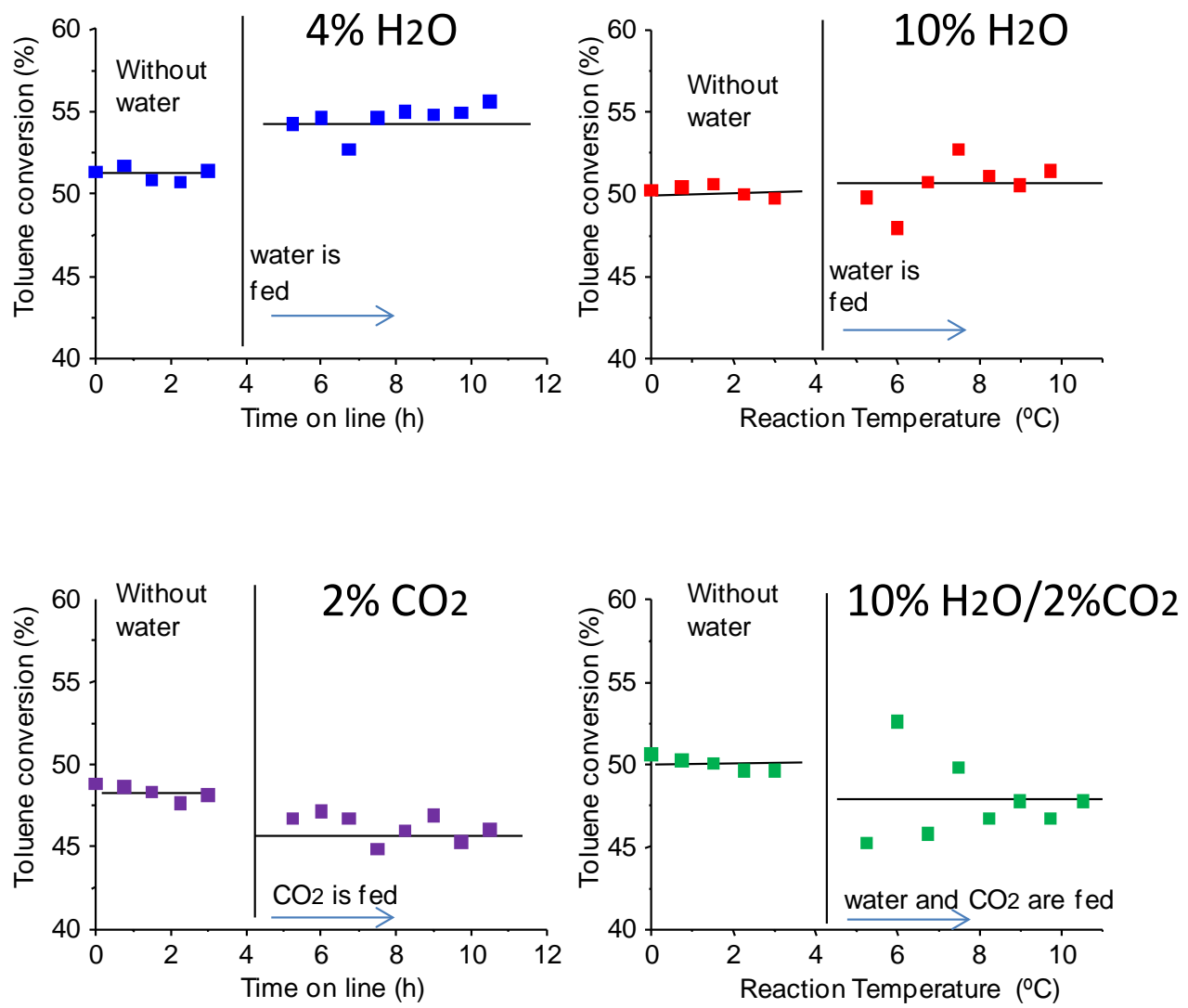

Figure 2. Toluene conversion under different reaction feeds. Toluene concentration: 200 ppm. Reaction temperature: $125^{\circ} \mathrm{C}$. GHSV: $6000 \mathrm{~h}^{-1}$.

Moreover, the addition of $\mathrm{CO}_{2}$ to the feed was not deleterious as only a subtle decrease of conversion is observed. The simultaneous addition of water and carbon dioxide did neither have an influence on the catalytic performance. Therefore, Mn-HT shows an outstanding activity and stability in relevant conditions.

In order to explain the remarkable catalytic activity of these catalysts a detailed characterization has been conducted. Firstly, textural characteristics of the samples were analysed by $\mathrm{N}_{2}$ adsorption/desorption isotherm measurements. Data are shown in Figure 3. Unexpectedly, Mn-HT displays a remarkable lower $\mathrm{S}_{\mathrm{BET}}$ value than Mn-ST, 29 vs. $108 \mathrm{~m}^{2} \mathrm{~g}^{-1}$, ruling out the relevant role of this parameter on the catalyst performance. The isotherms recorded for these materials correspond to Type IV isotherms usual for 
mesoporous samples. In all isotherms the hysteresis loop is rather narrow, making the denomination of the hysteresis type not easy. We use the adsorption branch of the isotherm to determine the mesopore size distribution, eluding the nitrogen adsorption artefact due to the steep desorption at $\mathrm{P} / \mathrm{P}_{0}$ of $0.4-0.5$. It is noteworthy that the mesopore volume for the sample obtained under solvothermal conditions (Mn-ST) shows a remarkable contribution of the pores lower than $10 \mathrm{~nm}$, whereas this contribution is marginal for the Mn oxide prepared under hydrothermal conditions.
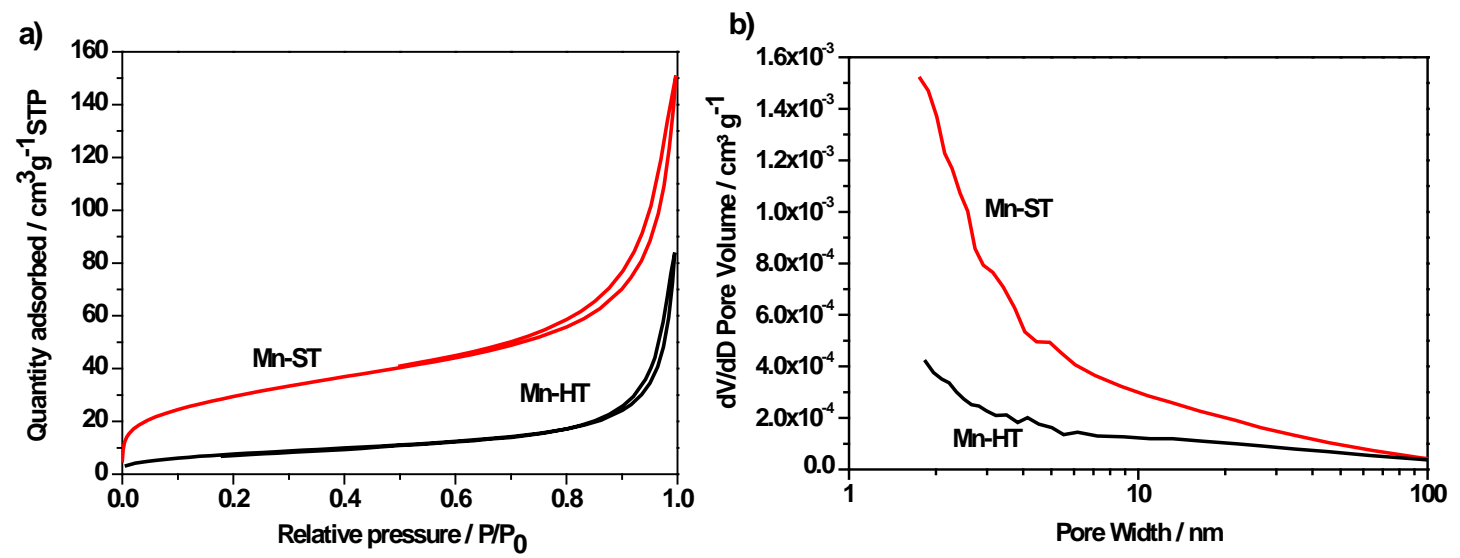

Figure 3. a) $\mathrm{N}_{2}$ adsorption/desorption isotherms and b) pore-size distributions for manganese catalysts.

Therefore, it seems that the synthesis under solvothermal conditions favours the formation of intraparticle porosity, which is hardly created under hydrothermal conditions, as corroborated later by microscopy analyses.

The main crystalline phase observed in both samples is $\mathrm{Mn}_{3} \mathrm{O}_{4}$ which is reported to be the most active crystalline phase of the manganese oxides for total oxidation reactions [11,35]. XRD patterns (Figure 4) permit to identify unambiguously that the two manganese catalysts present the spinel $\left(\mathrm{AB}_{2} \mathrm{O}_{4}\right.$, hausmannite) type structure belonging to the tetragonal crystal system and $I 4_{1} /$ amd space group. The unit cell comprises 32 
oxide ions and there are $8 \mathrm{Mn}^{2+}$ ions occupying the tetrahedral (A) sites and $16 \mathrm{Mn}^{3+}$ ions located in the octahedral (B) ones.

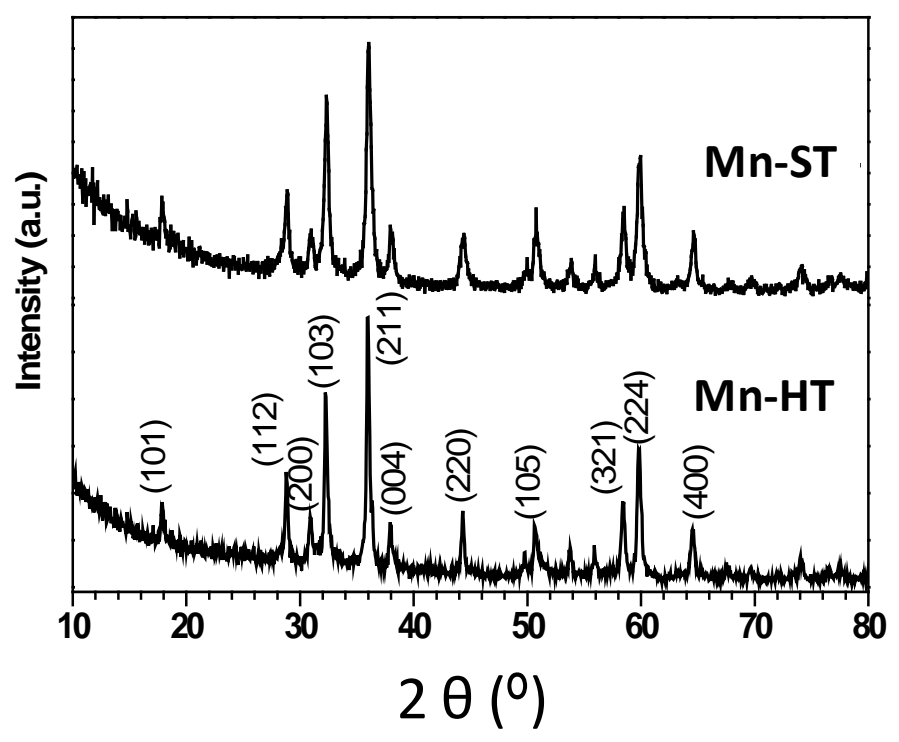

Figure 4. XRD patterns of manganese oxide catalysts.

Average crystallite sizes calculated from XRD patterns applying Double-Voigt approach reveals that the solvothermal synthesis produces materials with smaller crystallite size than the hydrothermal one, 9 and $19 \mathrm{~nm}$ respectively, which is also in line with the highest surface area of the Mn-ST sample. The higher particle size under hydrothermal conditions can be due to the fact that ethylene glycol is a less polar solvent than water, thus the solvation energy of the oxide/hydroxide phase is lower than in pure water. This leads to a higher initial energy of the oxide/hydroxide before nucleation and a lower energy barrier has to be overcome for crystallization. Consequently, the nucleation rate is higher in solvent-rich solutions, preventing the growth of bigger crystallites.

Moreover, structural analyses were made applying Rietveld analyses for both materials. The excellent results of refinement (Table 2) indicate the great influence of the solvent 
used during the synthesis procedure on the tetragonal cell parameters, a contraction of the unit cell occurs in "a” direction and elongation in the direction of "c" axis take place by increasing the mean particle size $<\mathrm{d}>$. As expected, the degree of tetragonal distortion of the unit cell increases with decreasing the particle size. Both samples show a defect in its structure. The refinements were done assuming that the octahedral sites are fully occupied by $\mathrm{Mn}^{3+}$ cations. SOF (site occupation factors) values for $\mathrm{Mn}^{2+}$ and oxygen atoms (Table 2) point out a defect in the cationic and anionic sites, respectively, which could explain the relevant activity of both catalysts. For the Mn-ST sample, $10 \%$ deficiency approximately exists in cationic sites containing $\mathrm{Mn}^{2+}$ that can arise from partial oxidation of $\mathrm{Mn}^{2+}$ to $\mathrm{Mn}^{3+}$ leading to formation of cationic vacancies. These are mainly compensated by the deficiency in the anionic sites ( 8\%) through formation of anionic vacancies and in fewer amounts via presence of interstitials (e.g., $\mathrm{OH}^{-}$). The calculated density for such sample from refinement data reveals a defected spinel structure, with a value of $4.63 \mathrm{~g} \mathrm{~cm}^{-3}$ in contrast with $4.86 \mathrm{~g} \mathrm{~cm}^{-3}$ for the ideal spinel structure (bulk material). 
Table 2. Rietveld analyses.

\begin{tabular}{ccc}
\hline Sample & $\mathrm{Mn}-\mathrm{ST}$ & $\mathrm{Mn}-\mathrm{HT}$ \\
\hline Phase name & $\mathrm{Mn}_{3} \mathrm{O}_{4}$ & $\mathrm{Mn}_{3} \mathrm{O}_{4}$ \\
Space group (No.) & $\mathrm{I} 41 / \mathrm{a} \mathrm{m} \mathrm{d} \mathrm{(141)}$ & $\mathrm{I} 41 / \mathrm{a} \mathrm{m} \mathrm{d}(141)$ \\
$\mathrm{R}_{\text {Bragg }}$ & 0.315 & 0.234 \\
$\mathrm{a}=\mathrm{b}(\AA)$ & 5.765 & 5.763 \\
$\mathrm{c}(\AA)$ & 9.425 & 9.444 \\
$\mathrm{c} / \sqrt{ } 2 \mathrm{a}$ & 1.14 & 1.16 \\
$\rho\left(\mathrm{g} / \mathrm{cm}^{3}\right)$ & 4.630 & 4.737 \\
$\mathrm{~V}\left(\AA^{3}\right)$ & 313.31 & 313.75 \\
$\mathrm{R}_{\mathrm{exp}}$ & 0.85 & 0.92 \\
$\mathrm{R}_{\mathrm{p}}$ & 0.80 & 0.88 \\
$\mathrm{R}_{\mathrm{wp}}$ & 1.01 & 1.12 \\
${ }_{\mathrm{GOF}}$ & 1.18 & 1.21 \\
${ }^{* *}$ s.o.f. / $\mathrm{Mn}^{2+}$ & 0.93 & 0.89 \\
${ }^{* *}$ s.o.f. / $\mathrm{Mn}^{3+}$ & 1.00 & 1.00 \\
${ }^{* * *}$ s.o.f. / $\mathrm{O}^{2-}$ & 0.97 & 0.92 \\
\hline
\end{tabular}

"GOF: goodness of fit. It compares $R_{w p}$ with $R_{\text {exp }}$. GOF $=1$ means the model is as good as possible. GOF values less than 4 are acceptable.

${ }^{* *}$ s.o.f.: site occupancy factor. s.o.f. $=1$ means every equivalent position for $x y z$ is occupied by that atom and s.o.f. $<1$ means some of the sites are vacant.

On the other hand, Mn-HT sample showed a less defected spinel structure with a calculated density of $4.74 \mathrm{~g} \mathrm{~cm}^{-3}$, in line with its higher mean crystallite size. However, a higher activity is observed for this catalyst. Significantly, $7 \%$ deficiency approximately exists in cationic sites containing $\mathrm{Mn}^{2+}$ but, contrary to what happened for the Mn-ST catalyst, defects are not mainly compensated by the deficiency in the anionic sites ( $2 \%)$ through formation of anionic vacancies but mainly by the presence of higher amounts of interstitials, likely structural water or interstitial $\mathrm{OH}^{-}$. Therefore, it can be assumed that the insertion into the crystalline structure of these species during the hydrothermal synthesis could be the driving factor for the better catalytic performance of this material. This fact could also explain the higher activity found in presence of water since the possible loss of structural water at those temperatures needed to reach full toluene conversion could be reduced under humid conditions. 
The mixed oxidation state of Mn, typical of hausmannite spinel, was also confirmed by the XPS results (Figure 5a) were the Mn 3s splitting value of $5.7 \mathrm{eV}$ corresponds to the mixed valence state of $\mathrm{Mn}^{2+}$ and $\mathrm{Mn}^{3+}$ with characteristic splitting values of $5.9 \mathrm{eV}$ and $5.5 \mathrm{eV}$, respectively [37, 38]. The Mn 2p $3 / 2$ peak (Figure 5b) is centered at $641.3 \mathrm{eV}$ and the $\mathrm{Mn} 2 \mathrm{p}_{1 / 2}$ peak at $653.1 \mathrm{eV}$, with a splitting of $11.8 \mathrm{eV}$, which is in good agreement with literature values [37, 38]. Moreover, deconvolution of Mn 2p spectral region allowed calculating a $\mathrm{Mn}^{2+}: \mathrm{Mn}^{3+}$ ratio 1:1.8 which is in good agreement with the stoichiometric value (1:2) but showing no differences among Mn-HT and Mn-ST catalysts. The slight discrepancies between the $\mathrm{Mn}^{2+}: \mathrm{Mn}^{3+}$ ratio determined by XPS and the bulk can be related to the presence of oxygen/cationic vacancies in the surface.

The asymmetrical O 1s signal can be deconvoluted into two components (Figura 5c). The peak at $529.5 \mathrm{eV}$ is attributed to the surface lattice oxygen $\mathrm{O}^{2-}$ whereas the broad shoulder at a higher $\mathrm{BE}(531.3 \mathrm{eV})$ assignation is more difficult, as this feature could either be the result of hydroxyl groups or alternatively might be due to the presence of oxygen vacancies, surface adsorbed oxygen, or carbonate species. 

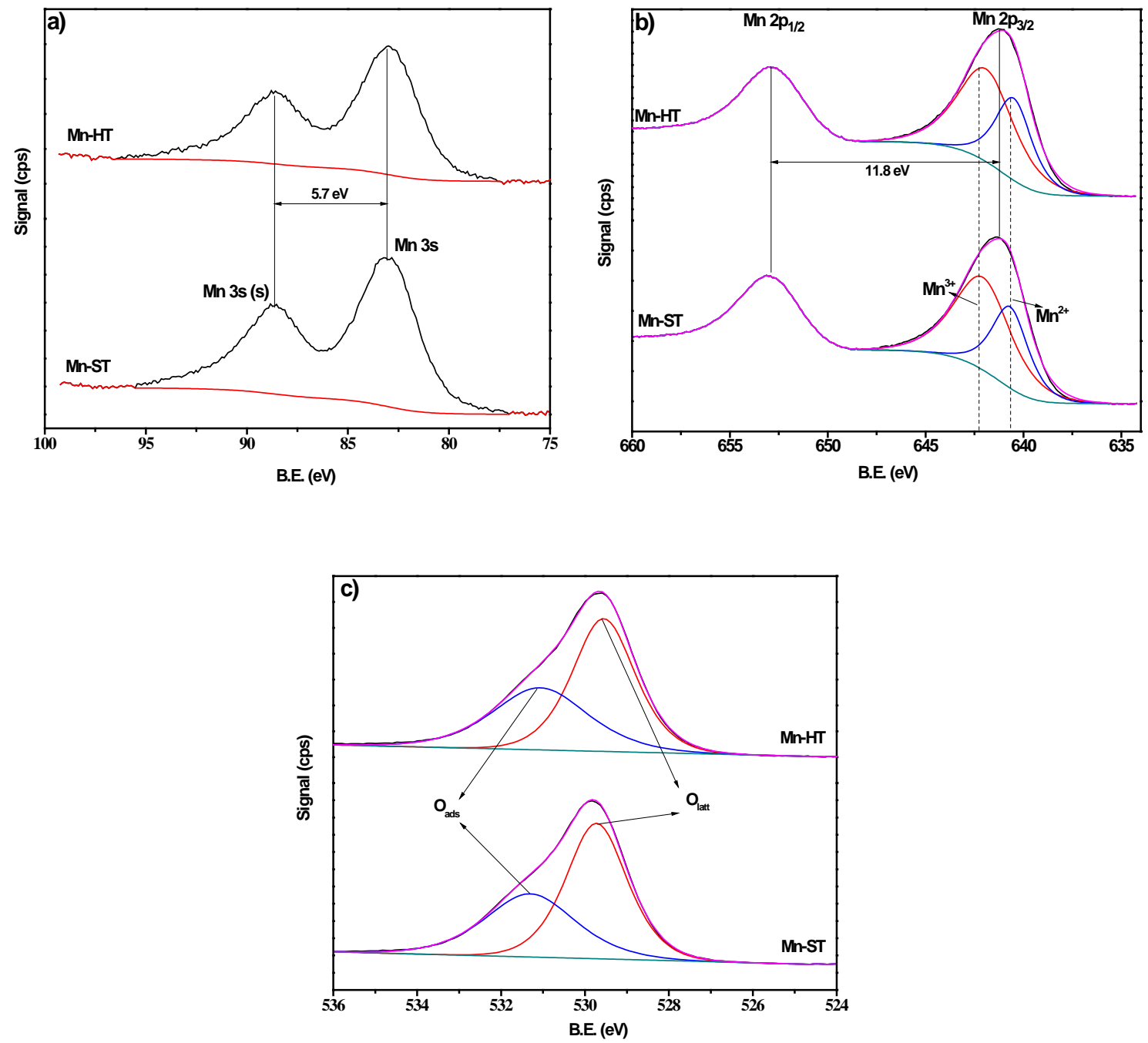

Figure 5. XPS spectra of the (a) Mn 3s region, (b) Mn 2p region and (c) $\mathrm{O}$ 1s region of the manganese oxide catalysts.

The reactivity of the oxygen species was investigated by $\mathrm{H}_{2}$-TPR analysis. The TPR profile of the $\mathrm{Mn}_{3} \mathrm{O}_{4}$ samples (Figure 6) shows a low-temperature band around 200$300^{\circ} \mathrm{C}$, which can be attributed to the reduction of $\mathrm{Mn}^{3+}$ ions located in the tetrahedral sites of the hausmannite lattice, and a wide signal in the $300-500^{\circ} \mathrm{C}$ temperature range, due to the hausmannite reduction $\left(\mathrm{Mn}_{3} \mathrm{O}_{4} \rightarrow \mathrm{MnO}\right)$. Since $\mathrm{MnO}$ is the final reduction product (terminating at ca. $700{ }^{\circ} \mathrm{C}$ ), the two peaks should reveal the reduction of two different $\mathrm{Mn}^{3+}-\mathrm{O}$ bonds (to $\mathrm{MnO}$ ) that are available in $\mathrm{Mn}_{3} \mathrm{O}_{4}$ [35]. The $\mathrm{H}_{2}$ consumption (4.3 mmol g-1), related to the $\mathrm{Mn}_{3} \mathrm{O}_{4} \rightarrow \mathrm{MnO}$ step, is in close agreement with the 
theoretical data. Although both Mn-catalysts present a similar profile, some relevant differences can be clearly appreciated in the low temperature reduction band. In this temperature range, it is clearly appreciated that $\mathrm{Mn}^{3+}$ in the tetrahedral sites of the hausmannite lattice are in two different chemical environments, being these species reduced around $200{ }^{\circ} \mathrm{C}$ and $250{ }^{\circ} \mathrm{C}$, respectively. In line with Rietveld refined data, these two different sites could be tentatively related to the presence of cationic vacancies compensated by either interstitials or anionic vacancies, respectively, being the reducibility of the former higher than that observed for the latter. Therefore, it can be observed in Figure 6 that there is a higher proportion of highly reactive oxygen species associated to cationic vacancies compensated by interstitials in the Mn-HT sample, which is also in line with its higher activity.

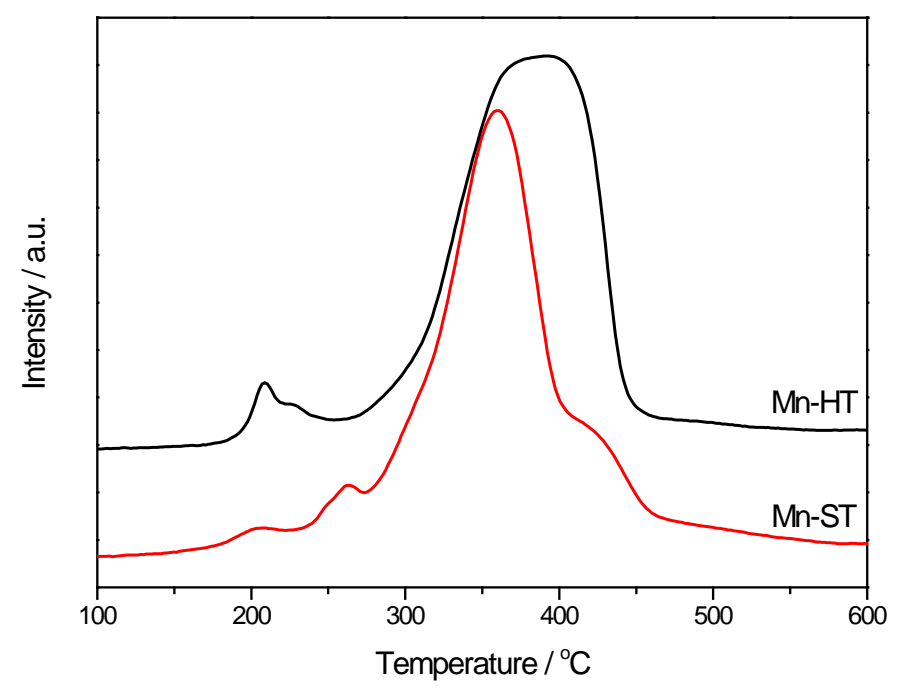

Figure 6. $\mathrm{H}_{2}$-TPR for the manganese oxide catalysts.

Electron microscopy observations show that the material named as Mn-ST exhibits a predominant phase composed of nanoparticles of around 10-40 nm (Figures 7a, 7b and S1). In all cases, the particles exhibited very good crystallinity in good agreement with the XRD data obtained and they can be indexed assuming $I 4_{1} /$ amd symmetry and lattice constants similar to the bulk $\mathrm{Mn}_{3} \mathrm{O}_{4}, \mathrm{a} \approx 5.7 \AA$ and $\mathrm{c} \approx 9.4 \AA$. Figure $7 \mathrm{~b}$ corresponds to a 
representative nanoparticle observed along the [111] orientation; a closer look at the atomic distribution is shown in Figure 7c with the model superimposed which allows the identification of all atoms in the structure. In this model, Mn is represented in green while $\mathrm{O}$ appears in red. Considering that all data was recorded using a High Angle Annular Dark Field Detector (HAADF) the contrast observed is dependent on the atomic number and thickness of the material. Therefore, the contrast variations observed in the nanoparticles analyzed (Figure 7a) are owed to the presence of cavities/roughness at the surface of the material, which is in line with the presence of pores lower than 5 $\mathrm{nm}$, as observed by $\mathrm{N}_{2}$ adsorption data.

The material obtained by hydrothermal synthesis, Mn-HT, presents a similar shape and a slightly higher particle size than the Mn-ST sample. Figure 7d depicts a low magnification image confirming the similar morphology of the material obtained under hydrothermal conditions composed of nanoparticles with various sizes. The crystallinity for every particle observed was also found to be very good as it occurred for Mn-ST, see Figure 7e, in perfect agreement with the tetragonal symmetry $I 4_{1} /$ amd. The highresolution data, Figure 7e and 7f, allow the visualization of the atomic distribution of the atoms along the [011] orientation, where the Mn atoms appear as green spheres while $\mathrm{O}$ are in red. Surprisingly, cavities/roughness are again appreciated, even in a higher amount (see Fig. S1d-S1f), despite that the presence of surface mesopores is hardly observed by $\mathrm{N}_{2}$ adsorption data. Therefore, it can be assumed that internal cavities/vesicles instead of surface mesopores are predominantly created during the hydrothermal synthesis, where water molecules could be occluded leading to highly active oxygen surface species, according to TPR data. 

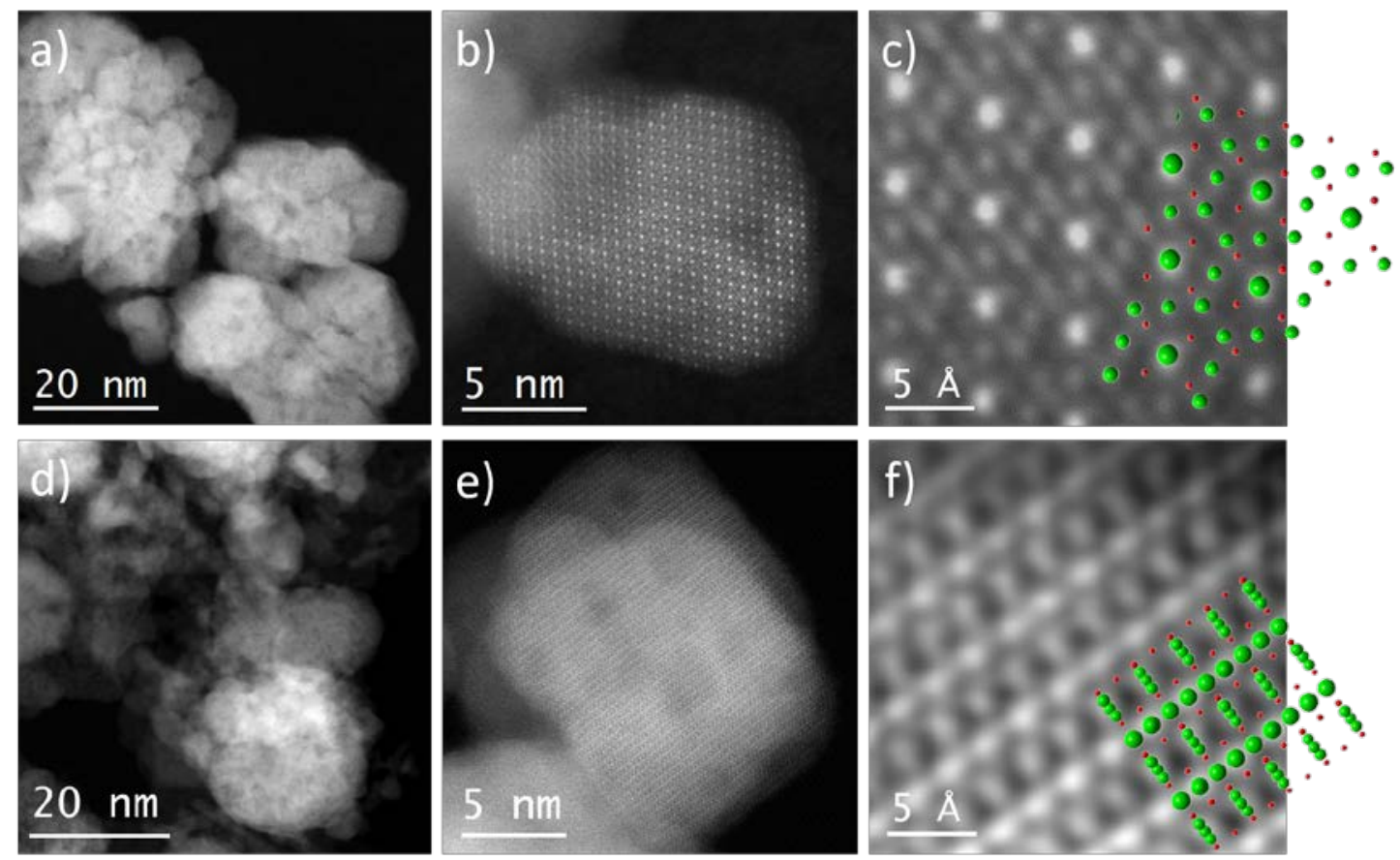

Figure 7. $\mathrm{C}_{\mathrm{s}}$-corrected STEM-HAADF data. a) Low-magnification image showing several Mn-ST nanoparticles. b) High-resolution image of a Mn-ST isolated nanoparticle along the [111] zone axis. c) A closer look of the structure of the Mn-ST nanoparticle with the model superimposed. d) Lowmagnification image of Mn-HT material. e) An isolated $\mathrm{Mn}_{3} \mathrm{O}_{4}-\mathrm{HT}$ nanoparticle along the [011] orientation. f) Enlarged image of the particle shown in e) with the model superimposed. Green spheres correspond to the Mn while $\mathrm{O}$ atoms appear as red spheres.

The chemical composition for both samples was corroborated by means of Energy dispersive X-ray Spectroscopy (EDS) and Electron Energy Loss Spectroscopy (EELS), see Figure 8, concluding that the $\mathrm{Mn}$ and $\mathrm{O}$ are equally distributed with no detectable compositional variations in any case. Figure 8a corresponds to the EDS map recorded over several nanoparticles proving the homogeneous composition for every particle. The EELS spectrum image appears in Figure 8b. For this case, an isolated nanoparticle was analyzed in order to observe any variations along the nanoparticle (if any). A homogeneous distribution was obtained for both samples. 

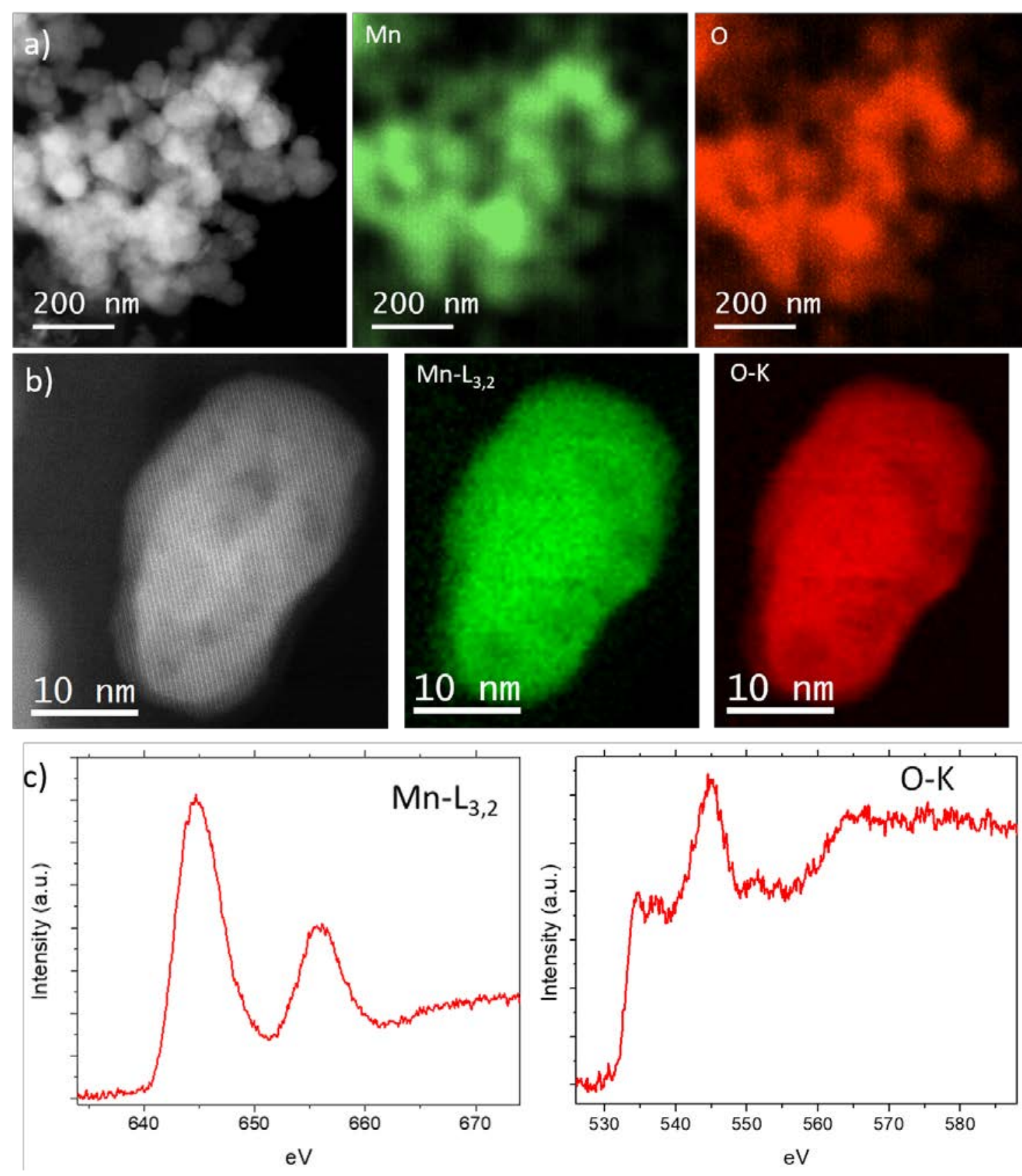

Figure 8. Study by TEM of Mn-HT catalyst. a) EDS mapping analysis of several nanoparticles which confirms the presence of Mn (green map) and O (red map). b) EEL spectrum image of a MnHT nanoparticle showing the perfect concordance between the Mn and O. c) EEL spectra of the signals extracted corresponding to $\mathrm{Mn}$ and $\mathrm{O}$ edges respectively.

Considering the similarities between the products obtained by means of both synthetic methods, we believe that the differences observed in their catalytic performance can be explained in terms of the type of cavities created during the preparation method. As already mentioned, all NPs show contrast variations in the images that are attributed to 
the presence of a rough surface, as the chemical composition has been found to be homogeneous with the same $\mathrm{Mn}: \mathrm{O}$ ratio. With the intention of gaining more information about this assumption SEM analyses were performed (Figure 9) showing that for Mn-ST there are more interparticle voids, resulting in a higher surface area. For both samples, Mn-ST and Mn-HT, the morphology of the materials is very similar observing three main products sphere-like particles, elongated particles with plate morphology and nano-fibers type formations, which could be attributed to manganese hydrated phases [39], see figure 9. Figures 9a and 9b present the SEM observations at low and at high magnification for the Mn-ST material. It is possible to observe the presence of spherical-like particles all over the sample. In the high-resolution SEM data it is possible to visualize the channels opened to the surface of these nanoparticles, which make them look like if they were agglomerated entities but we know for a fact after the STEM analysis that they are single individual crystals.

After observation of the Mn-HT at low-magnification Figure 9c, it is appreciated a more heterogeneous material, with the plates and nano-fibers also present. These structures were also observed in Mn-ST but into a less extent. By looking closer at the nanoparticles formed by this synthetic method, Figure 9d, it is also possible to visualize a similar morphology as observed for Mn-ST, but in this case less porosity appears, making the material more compact exposing less open pores opened to the surface giving as a result a lower adsorption capability.

Meanwhile, despite of the similarities, for Mn-HT the particles are more compact and exposing less accessible pores opened to the surface. By analysing several nanoparticles and in line with $\mathrm{XRD}, \mathrm{H}_{2}-\mathrm{TPR}$ and $\mathrm{N}_{2}$ adsorption data, it appears that the Mn-HT contains more internal cavities where water molecules can be retained, leading to highly 
active surface oxygen vacancies. These sites could act as reaction sites increasing the catalytic performance.
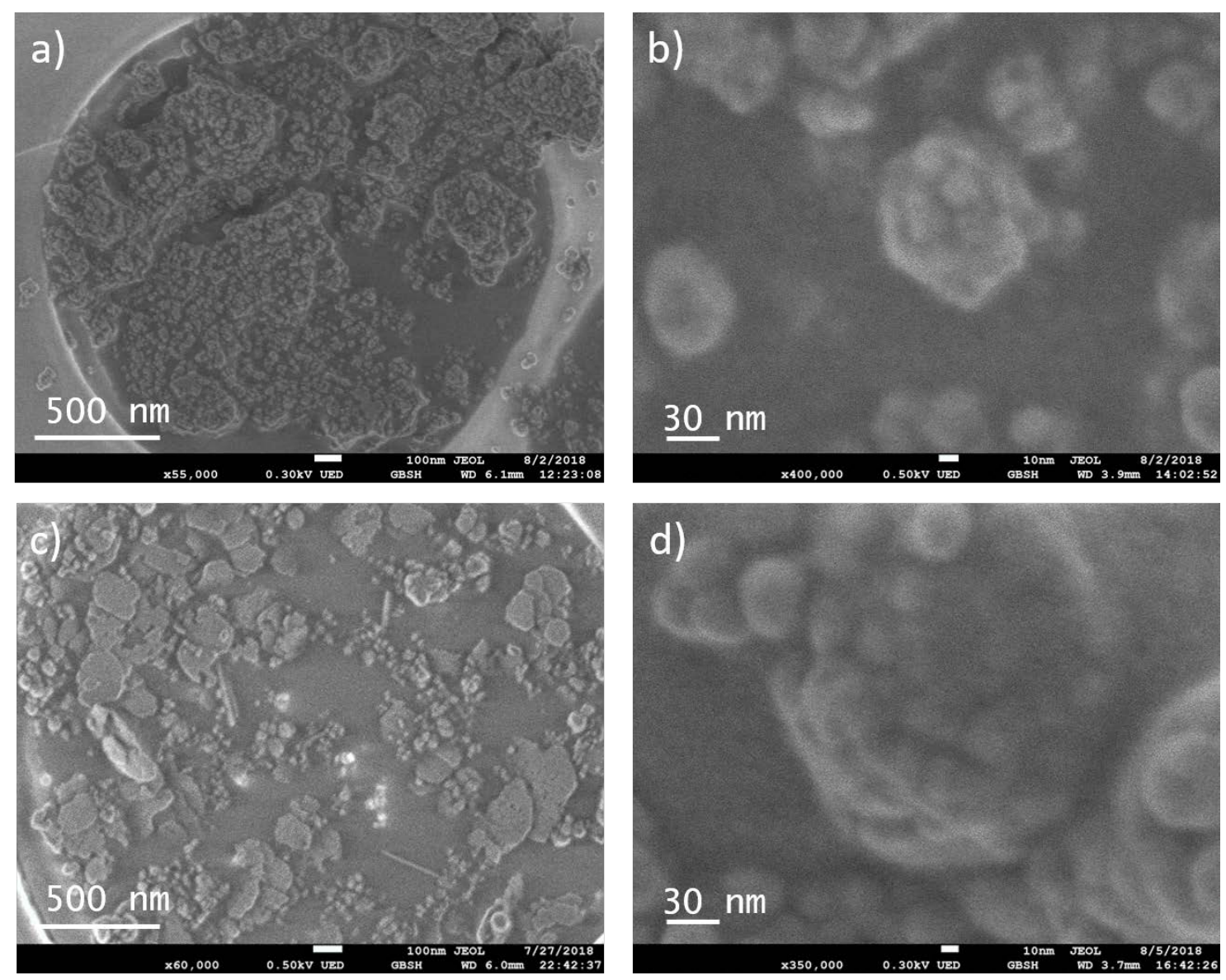

Figure 9. SEM observations of Mn-ST, a) Low-magnification and b) High-magnification images.

And Mn-HT c) Low-magnification and d) High-magnification images.

Manganese oxide synthesized by an easy hydrothermal method show very high catalytic activity and using low space velocities can completely remove toluene at temperatures very low $\left(150-175^{\circ} \mathrm{C}\right)$. This performance does not vary and after several cycles the same behaviour is observed. This stable behaviour is likely due to the fact that the temperature this material has been heat-treated $\left(180^{\circ} \mathrm{C}\right)$ is higher than that required for total conversion and then the structural and surface modifications after the catalytic tests are not important. The extremely high catalytic activity of this $\mathrm{Mn}_{3} \mathrm{O}_{4}$ catalyst can be 
due to the presence oxygen surface species which are highly reactive. The presence of $\mathrm{Mn}_{3} \mathrm{O}_{4}$ nanoparticles with a high concentration of $\mathrm{Mn}^{3+}$ at the tetragonal distorted cationic sites does likely play an important role. Interestingly, there are internal cavities/vesicles in the $\mathrm{Mn}_{3} \mathrm{O}_{4}$ structure which induces the presence of structural water.

\section{Conclusions}

Highly active manganese oxide catalyst has been synthesised using a simple and green synthesis method employing a hydrothermal procedure. A catalyst with remarkable higher activity is obtained by this method in spite of the fact that the surface area of the hydrothermal catalyst is ca. 4 times lower than that of the catalyst prepared by a solvothermal method. This catalyst has been tested in the total oxidation of toluene showing total conversion at only $175^{\circ} \mathrm{C}$ in the absence of water and, more remarkably, at $150^{\circ} \mathrm{C}$ using low concentrations of water. In view of the characterization of these catalysts and in line with literature data [32], the outstanding catalytic activity of the $\mathrm{Mn}_{3} \mathrm{O}_{4}$ catalyst prepared by the hydrothermal method can be ascribed to the presence of highly reactive oxygen surface species. This species are likely promoted due to the existence of $\mathrm{Mn}_{3} \mathrm{O}_{4}$ nanoparticles with a relevant amount of $\mathrm{Mn}^{3+}$ at the tetragonal distorted cationic sites, likely compensated by structural water at the anionic sites. Interestingly, the presence of structural water seems to be a consequence of the formation of internal cavities/vesicles in the $\mathrm{Mn}_{3} \mathrm{O}_{4}$ crystalline structure.

\section{Acknowledgements}

AM thanks the National Natural Science Foundation of China (21850410448) and

(21835002). Authors from UCM thank Santander-UCM institution (PR41/17-20951 project) and MINECO (MAT2017-84118-C2-2-R project). TG and JML thanks 
Regional Aragon Government (DGA) under the research groups support programme. Electron microscopy analyses were performed at Centre for High-Resolution Electron Microscopy (ChEM), ShanghaiTech University. Some of the STEM analyses were conducted at the Laboratorio de Microscopias Avanzadas, Universidad de Zaragoza, Spain. R. A. acknowledges support from Spanish MINECO grant MAT2016-79776-P (AEI/FEDER, UE). Authors from UV thank MINECO (MAT2017-84118-C2-1-R project) for funding.

\section{References}

1 L. F. Liotta, Appl. Catal. B: Environ. 100(3-4) (2010) 403-412.

2 Z. Chen, J. Ma, R. Zhou, Appl. Surf. Sci. 465 (2019) 15-22.

3 R. Balzer, L. F. D. Probst, V. Drago, W. H. Schreiner and H. V. Fajardo, Braz. J. Chem. Eng. 31 (2014) 757-769.

4 B. Solsona, T.E. Davies, T. García, I. Vázquez, A. Dejoz and S.H. Taylor, Appl. Catal. B: Environ. 84 (2008) 176-184.

5 T. García, D. Sellick, F. Varela, I. Vázquez, A. Dejoz, S. Agouram, S. H. Taylor, and B. Solsona, Appl. Catal. A: Gen., 450 (2013) 169- 177.

6 J. Luo, Q. Zhang, A. Huang and S. L. Suib, Micropor. Mesopor. Mater. 35-36 (2000) 209-217.

7 C. Lahousse, A. Bernier, P. Grange, B. Delmon, P. Papaefthimiou, T. Ioannides and X. Verykios, J. Catal. 178 (1998) 214-225.

8 W. Si, Y. Wang, Y. Peng, X. Li, K. Lim, J. Li, Chem. Commun. 51 (2015) 1497714979.

9 S. S. T. Bastos, J. J. M. Orfao, M. M. A. Freitas, M. F. R. Pereira and J. L. Figueiredo, Appl. Catal. B: Environ. 93 (2009) 30-37. 
10 S. S. T. Bastos, S. A. C. Carabineiro, J. J. M. Órfao, M. F. R. Pereira, J. J. Delgado and J. L. Figueiredo, Catal. Today, 180 (2012) 148-154.

11 S. C. Kim and W. G. Shim, Appl. Catal. B: Environ., 98 (2010) 180-185.

12 H.Pan, Y. Jian, C. Chen, C. He, Z. Hao, Z. Shen, H. Liu, Environ. Sci. Technol. 51 (2017) 6288-6297.

13 H. Sun, S. Chen, P. Wang and X. Quan, Chem. Eng. J., 178 (2011) 191-196.

14 Y. S. Ding, X. Shen, S. Sithambaram, S. Gomez, R. Kumar, M. B. Vincent and S. L. Suib, Chem. Mater. 17 (2005) 5382-5389.

15 Z. Sihaib, F. Puleo, J. M. Garcia-Vargas, L. Retailleau, C. Descorme, L. F. Liotta, J. L. Valverde, S. Gil and A. Giroir-Fendler, Appl. Catal. B: Environ. 209 (2017) 689700.

16 J. Chen, X. Chen, W. Xu, Z. Xu, J. Chen, H. Jia, J. Chen, Chem. Eng. J. 330 (2017) 281-293.

17 Y. Wang, L. Zhang, L. Guo, ACS Appl. Nano Mater. 1 (2018) 1066-1075.

18 J. A. Darr, J. Zhang, N. M. Makwana, X. Weng, Chem. Rev. 117 (2017) $11125-11238$.

19 M. Shandilya, R. Rai \& J. Singh, Advances in Applied Ceramics, 2016, DOI: 10.1080/17436753.2016.1157131.

20 B. Patel, M. Guo, A. Izadpanah, N. Shah, K. Hellgardt, Bioresource Technology 199 (2016) 288-299.

21 G. Canua, V. Buscaglia, Cryst. Eng. Comm. 19 (2017) 3867-3891.

22 Q. Yang, Z. Lu, J. Liu, X. Lei, Z. Chang, L. Luo, X. Sun, Progress in Natural Science: Materials International, 23, 4, (2013) 351-366.

23 X. Li, X. Lv, N. Li, J. Wu, Y.-Z. Zheng, X. Tao, Appl. Catal. B: Environ. 243 (2019) 76-85. 
24 B. Naresh, D. Punnoose, S. Srinivasa Rao, A. Subramanian, B. Raja Ramesh, HeeJe Kim, New J. Chem. 42 (2018) 2733-2742.

25 B.Jansi Rani, G.Ravi, R. Yuvakkumar, S. Ravichandran, Fuad Ameen, S. Al Nadhary, Renewable Energy 133 (2019) 566-574.

26 T. Tsoncheva, G. Issa, I. Genova, M. Dimitrov, D. Kovacheva, J. Henych, M. Kormunda, N. Scotti, J.Tolasz, V. Štengl, Microp. Mesop. Mater. 276 (2019) 223231.

27 H.-R. Xia, W.-T. Sun, L.-M Peng, Chem. Commun. 51 (2015) 13787-13790.

28 X. Jia, X. Wu, B. Liu, Dalton Trans. 47 (2018) 15506-15511.

29 G. Qiu, H. Huang, S. Dharmarathna, E. Benbow, L. Stafford, S.L. Suib, Chem. Mater. 23(17) (2011) 3892-3901.

30 H-J Chen, W. Tian, W. Ding, Adsorption Science \& Technology, 36 (2018) 11001111.

31 M. P. Pico, I. Álvarez-Serrano, M. L. López, M. L. Veiga, Dalton Trans., 43 (2014) 14787.

32 S. Ge, X. Shi, K. Sun, C. Li, J. R. Baker, M. M. Banaszak Holl, B. G. Orr, J. Phys. Chem. C 113 (2009) 13593-13599.

33 C. Doornkamp, V. Ponecr, J. Molec. Catal. A: Chem. 162 (2000) 19-32.

34 S. Todorova, A. Naydenov, H. Kolev, G. Ivanov, A. Ganguly, S. Mondal, S. Saha, A. K. Ganguli, Reac. Kinet. Mech. Cat. 123 (2018) 585-605.

35 M. Piumetti, D. Fino and N. Russo, Appl. Catal. B: Environ., 163 (2015) 277-287.

36 J. Li, L. Li, F. Wu, L. Zhang and X. Liu, Catal. Comm. 31 (2013) 52-56.

37 J. W. Lee, A. S. Hall, J. D. Kim and T. E. Mallouk, Chem. Mater. 24 (2012) 11581164. 
38 G. Zhao, J. Li, W. Zhu, X. Ma, Y. Guo, Z. Liu and Y. Yang, New J. Chem.40 (2016) 10108-10115.

39 Y. Ruiz-Heredia, I. Álvarez-Serrano, M.L. López, C. Pico and M.L. Veiga, J. Supercrit. Fluids, 78 (2013) 21-27.

40 Kai Qi, Junlin Xie, De Fang, Xiaoqing Liu, Pijun Gong, Fengxiang Li, Da Han, Feng He, Mater. Chem. Phys. 209 (2018) 10-15.

41 J. Darul, C. Lathe, P. Piszora, J. Phys. Chem. C 117 (2013) 23487-23494. 